\title{
The urban heat island effect on frost damage of natural building stones.
}

\author{
Daphne Guilbert ${ }^{1,3}$, Tim De Kock ${ }^{1}$, Steven Caluwaerts ${ }^{2}$, Veerle Cnudde ${ }^{1}$, Klaas Calle $^{3}$ and \\ Nathan Van Den Bossche ${ }^{3}$ \\ ${ }^{1}$ PProGRess, Department of Geology, Ghent University, Krijgslaan 281 S8, 9000 Ghent, Belgium \\ ${ }^{2}$ Atmospheric Physics, Department of Physics and Astronomy, Ghent University, Krijgslaan 281 S9; \\ 9000 Ghent, Belgium \\ ${ }^{3}$ Building Physics Group, Department of Engineering and Architecture, Sint-Pietersnieuwstraat 41 \\ B4, 9000 Ghent, Belgium
}

\begin{abstract}
Climate plays a major role in the weathering of building stones. This study specifically investigates the influence of the urban heat island (UHI) in Ghent, Belgium, on freeze-thaw (F-T) weathering of natural building stones and their hydrophobic equivalent. Climatic analysis of data of two places in and around Ghent indicates higher temperatures and lower wind speeds in the city center. This leads to a reduced number of F-T cycles and a lower wind-driven load. Hygrothermal modelling of a natural building stone, Savonnières limestone, is performed for the urban and rural climate of Ghent on the untreated limestone and on the treated limestone to assess the freeze-thaw risk inside these materials. Urban climate has a mitigating effect on the potential frost risk in natural building stones as a result of the urban heat island. Additionally, the application of a water repellent product reduces the potential frost risk even more, since the water density in the stone is reduced.
\end{abstract}

\section{Introduction}

Building stones are strongly susceptible to weathering, which is triggered to the prevailing climate and air pollution (e.g. $[1,2])$. Several weathering mechanisms are already studied in function of the climate and climate change. Bonazza et al. [3] studied the impact of climate change of limestone surface recession, while Grossi et al. [4] studied this climate change impact on salt weathering and Bonazza et al. [5] studied the thermal stress on marbles. The influence of the climate change on freeze-thaw risk is studied by Grossi et al. and Lisø et al. $[6,7]$.

Most deterioration processes are driven by the presence of moisture (e.g. frost damage, biocolonization, salt damage...). Several methods are used to reduce wetting of wall assemblies by wind driven rain. A common method is the application of a water repellent layer on the pore walls of the outer layer of the wall assembly, which reduces the water absorption coefficient of the wall, without substantially changing the drying rate of the material.

Since weathering of building stones is dependent on the prevailing climate, the influence of the urban climate, and more importantly the urban heat island, should be 
studied as well. The urban heat island is the result of the increased temperature inside cities caused by the extensive use of manmade materials, anthropogenic heat and the reduction of vegetation. In this paper, the impact of the urban heat island on the freeze-thaw risk of a natural building stone and its water-repellent equivalent is studied with Heat, Air and Moisture modelling (HAM) after a thorough climate analysis.

\section{Materials and methods}

\subsection{Natural building stones}

For the assessment of the freeze-thaw risk in function of the prevailing climate, HAM simulations will be performed on Savonnières limestone, a natural building stone frequently used in Belgium as building material since the mid $-19^{\text {th }}$ century. Savonnières limestone [8] is a French limestone from the Meuse department, belonging to the Oolith Vacuolaire (Tithonian, Late-Jurassic) stratigraphic unit. It is a heterogeneous oolithic limestone with open porosity between $30-45 \%$ and a water absorption coefficient of approximately $0.072 \mathrm{~kg} / \mathrm{m}^{2} \mathrm{~s}^{1 / 2}$.

\subsection{Climatic analysis}

Climatic analysis is performed of a rural and an urban location in and around Ghent. Ghent is a middle-sized western-European city, with approximately 260000 inhabitants, and is situated $50 \mathrm{~km}$ from the North Sea. Its climate is classified as a Cfb climate, which is a humid and temperate, maritime climate according to the Köppen-Geiger climate scheme. The centre is densely built, while the rural surroundings are less densely built with a high fraction of green. Climatic data of the two locations is provided by the MOCCA project (Monitoring the City's Climate and Atmosphere) [9] for the period July 2016 - June 2017.

Analysis of the climatic data is performed by defining different frost parameters to evaluate the differences in frost behaviour between urban and rural environment. The amount of freeze-thaw days $\left(\mathrm{FTC}_{24 \mathrm{~h}}\right)$ is defined by the number of days with a negative crossing of $0{ }^{\circ} \mathrm{C}$. Additionally, frost intensity is calculated, based on $[6,10]$, in order to incorporate the temperature. This parameter is defined by the square root of the sum of the average negative temperatures of freezing days.

\subsection{HAM simulations}

The climatic data of the two locations is used in Delphin, a HAM program, developed by Bauklimatik Dresden, to assess the climatic impact on the frost risk of natural building materials. An inside climate with constant temperature of $20^{\circ} \mathrm{C}$ and relative humidity of $50 \%$ is chosen. Planar horizontal transport through a 1D construction with dimensions $100 \times 200 \mathrm{~mm}^{2}$, is assumed. Savonnières limestone and Savonnières limestone treated with a water repellent product are simulated to assess the impact of the characteristics of the material on the frost risk. The simulations consist of 5 years of preconditioning and 1 year with daily outputs for water density and ice density.

The treated Savonnières sample is defined as $1 \mathrm{~mm}$ of water repellent material and $199 \mathrm{~mm}$ of non-treated material. The water repellent material is defined according to the first method of Künzel [11], where the absorption coefficient equals $0 \mathrm{~kg} / \mathrm{m}^{2} \mathrm{~s}^{0.5}$. Since an absorption coefficient of $0 \mathrm{~kg} / \mathrm{m}^{2} \mathrm{~s}^{0.5}$ is not possible in the software, an absorption coefficient of $1^{-150} \mathrm{~kg} / \mathrm{m}^{2} \mathrm{~s}^{0.5}$ is assumed. The liquid water conductivity at effective 
saturation changes with the adjusted absorption coefficient, leading to a liquid water conductivity of $9.52237^{-307} \mathrm{~s}$.

\section{Results and discussion}

\subsection{Climatic analysis}

The urban heat island of Ghent is evaluated by the climatic analysis of the MOCCA climatic data of two locations in and around Ghent during the 2016-2017 winter (Table 1). The annual average temperature is $1{ }^{\circ} \mathrm{C}$ higher in the city centre of Ghent. In addition, this analysis indicates $39 \%$ less freezing hours in the urban location compared to the rural location The number of freeze-thaw days $\left(\mathrm{FTC}_{24 \mathrm{~h}}\right)$ is $33 \%$ higher in the rural location, while the frost intensity is $41 \%$ higher at this location. This illustrates that the urban heat island has an substantial influence on the frost intensity parameters and thus on the frost risk of materials. Furthermore, the analysis indicates a similar amount of precipitation in one year in both locations. It is also observed that the average wind speed at $2 \mathrm{~m}$ height in the urban landscape is reduced relative to the average wind speed in the rural area. This reduction is probably due to the presence of buildings and thus shielding of the wind.

Table 1. Results climatic analysis of rural and urban location of Ghent.

\begin{tabular}{|c|c|c|}
\hline & Rural & Urban \\
\hline $\mathrm{T}_{\text {mean }} 1$ year $\left({ }^{\circ} \mathrm{C}\right)$ & 11.5 & 12.6 \\
\hline${\text { Hours } \mathrm{T}_{\text {mean }}<0^{\circ} \mathrm{C}} \mathrm{FTC}_{24 \mathrm{~h}}$ & 457 & 279 \\
\hline Frost intensity & 43 & 25 \\
\hline Precip. 1 year $(\mathrm{mm})$ & 4.7 & 2.8 \\
\hline Average windspeed $@ 2 \mathrm{~m}(\mathrm{~m} / \mathrm{s})$ & 2.09 & 0.85 \\
\hline
\end{tabular}

The intensity of the urban heat island is dependent on the meteorological conditions. During windy or cloudy conditions is the effect significantly lower than during calm, clear nights (Figure 1). Differences in temperatures up to $6{ }^{\circ} \mathrm{C}$ during calm and clear nights are observed for Ghent. During cloudy or windy conditions, however, temperature differences between $0{ }^{\circ} \mathrm{C}$ and $1{ }^{\circ} \mathrm{C}$ are observed. This leads to differences in the freeze-thaw cycles in both locations and thus in differences in frost risk of building materials. The frost risk is higher in rural location during calm, clear sky conditions but is similar in both locations during windy or cloudy conditions. 


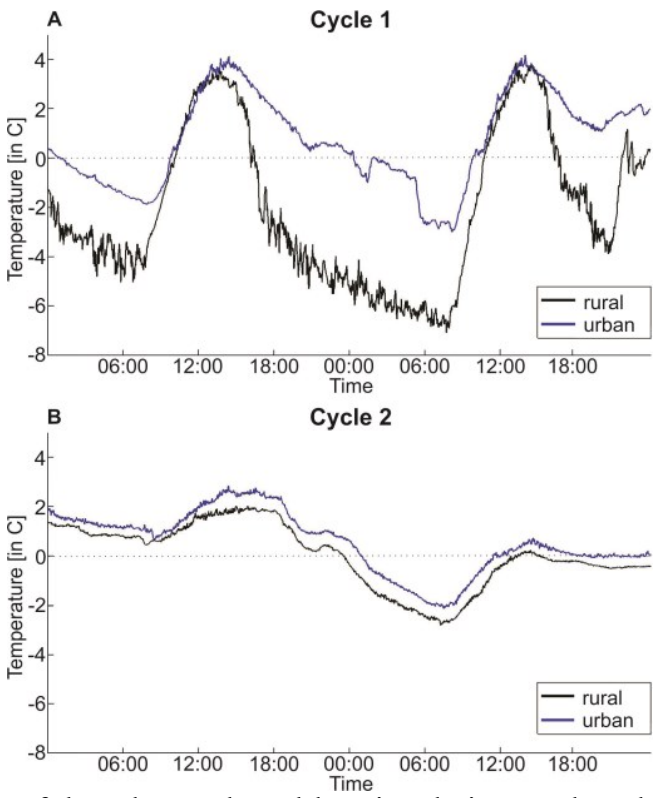

Fig. 1. Temperature trends of the urban and rural location during a calm, clear sky cycle (Cycle 1) and during a cloudy cycle (Cycle 2) to indicate the difference between various cycles.

\subsection{HAM simulations}

Figure 2 shows the trend of the total water density $\left(\mathrm{kg} / \mathrm{m}^{3}\right)$ in respectively untreated and treated Savonnières limestone for the rural and urban climate of Ghent during the period $1^{\text {st }}$ July $2016-30^{\text {th }}$ June 2017. During these simulations stones with a depth of $0.2 \mathrm{~m}$ are assumed.

The outputs for water density in the untreated Savonnières limestone show that the stone is relatively wet $\left(70 \mathrm{~kg} / \mathrm{m}^{3}\right)$ throughout the whole year, with episodes of higher water density as the result of intense rainfalls. In the rural location, the stone has higher water densities that penetrates deeper in the stone than in the urban location. This is partially the result of the higher wind speed and thus of a higher wind driven impact. In addition, the inner side of the stone is more wet in the rural location compared to the urban location. This is the result of the larger temperature difference between the stone (approx. $2{ }^{\circ} \mathrm{C}$ ) and the inside climate $\left(20^{\circ} \mathrm{C}\right)$. Due to this relatively high temperature difference, condensation occurs at this side of the stone, resulting in relatively high water densities.

The outputs of the treated Savonnières limestone show an important difference between rural and urban environment. The stone in urban environment shows sporadically a water density higher than $0.5 \mathrm{~kg} / \mathrm{m}^{3}$. These events with higher water density agree with the intense rain falls observed in the untreated samples. In rural area, events with high water density at the inner side of the stone are observed. They are the result of the large temperature difference between the inner side of the stone and the inside temperature. This temperature difference is higher in the rural stone, where lower temperatures are observed and thus more water condensates. Water densities up to $10 \mathrm{~kg} / \mathrm{m}^{3}$ are observed in this output. The inner side of stones with a larger thickness is less affected by the outside temperature and have thus a lower water density than stones with a smaller thickness. For example, a similar simulation is performed on a Savonnières limestone with dimensions $100 \times 100 \mathrm{~mm}^{2}$ and $100 \times 500 \mathrm{~mm}^{2}$. The inner side of the thinnest stone $\left(100 \times 100 \mathrm{~mm}^{2}\right)$ contains $100 \mathrm{~kg} / \mathrm{m}^{2}$ water, while the inner side of the thickest stone $\left(100 \mathrm{x} 500 \mathrm{~mm}^{2}\right)$ contains almost $0 \mathrm{~kg} / \mathrm{m}^{3}$ water. 


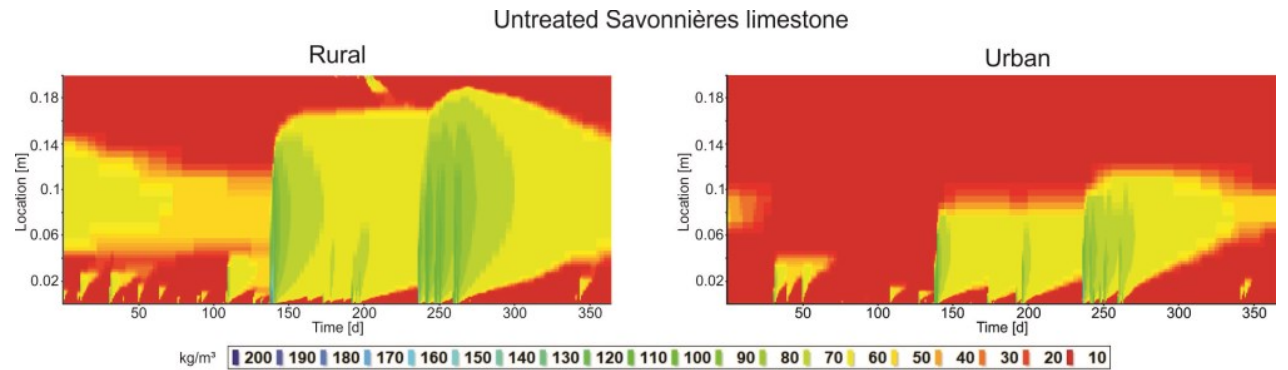

Treated Savonnières limestone
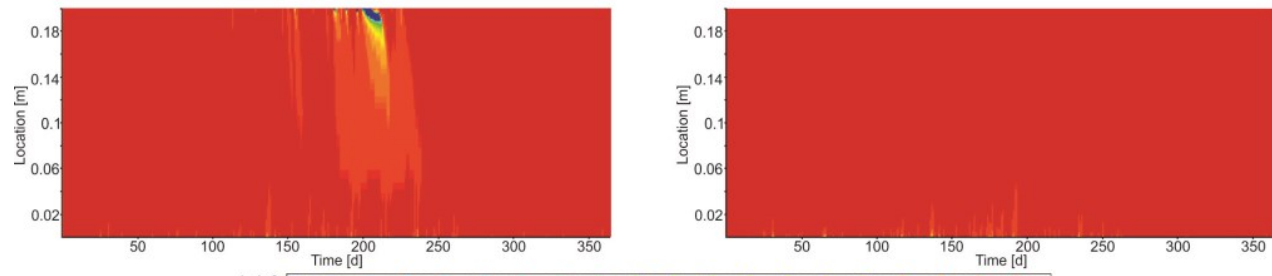

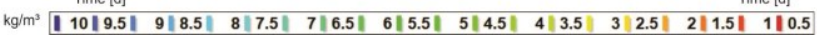

Fig. 2. Water density in untreated (above) and treated (below) Savonnières limestone in rural (left) and urban (right) environment; with time in days in abscissa and stone depth in ordinate with outside climate run $=0 \mathrm{~m}$.

Figure 3 shows the trends of the ice density inside the untreated and treated stones in both rural and urban environment. Because of the colder outside temperatures in the rural location, more ice is formed in the untreated stone in this location compared to the urban location, where no ice is formed in the untreated stone. The thickness of the stone has an important influence on the amount of ice formed inside. Similar simulations on a Savonnières limestone with a thickness of $50 \mathrm{~cm}$ indicates deeper and more ice formation in both locations. Nevertheless, the amount of ice formation is always higher in the rural location, leading to a higher frost impact on a rural situated stone.
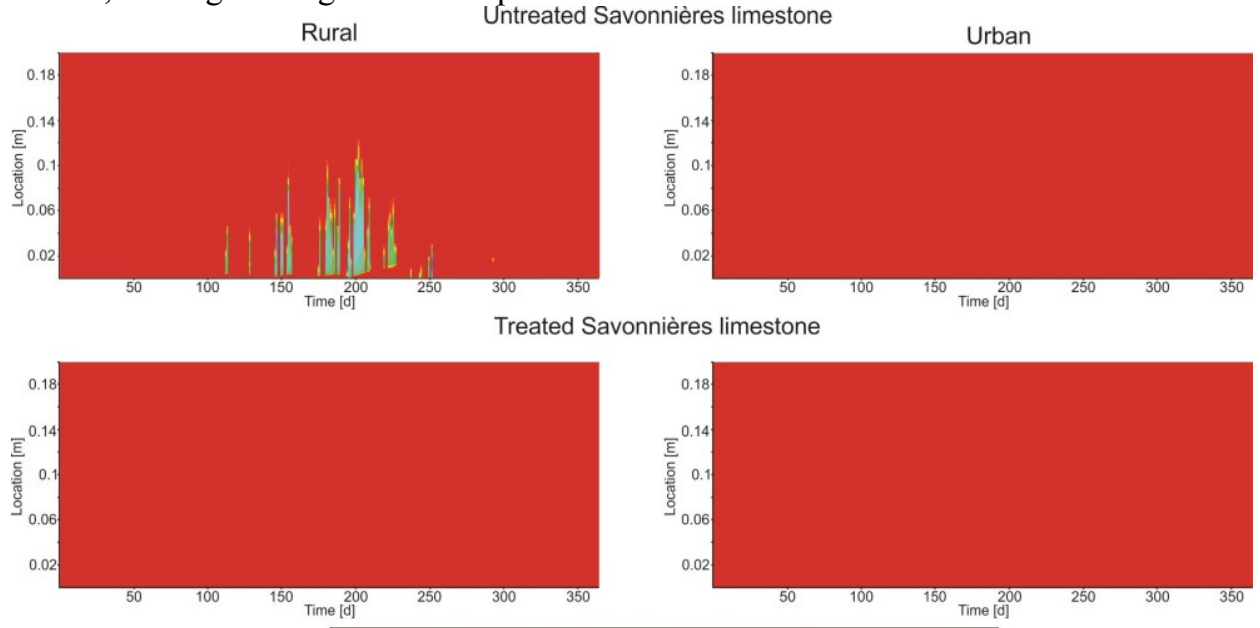

Fig. 3. Ice density in untreated (above) and treated (below) Savonnières limestone in rural (left) and urban (right) environment; with time in days in abscissa and stone depth in ordinate with outside climate run $=0 \mathrm{~m}$.

The outputs for the treated Savonnières limestone indicates no ice formation in both locations. This is due to the reduced amount of water present in the pores. The same simulation on a treated Savonnières limestone with dimensions $100 \times 100 \mathrm{~mm}^{2}$ indicates ice formation inside the rural situated stone as a result of the high amount of water that 
condensates on the inner side of the stone. This similar simulation indicates again no ice formation in the urban location.

These results indicate that the potential frost damage risk is mitigated in urban environment due to the urban heat island and the reduced wind speed. The application of a water repellent product reduces the water density in the stone, and consequently the amount of ice formed.

However, the definition of the water repellent layer in the HAM program is not realistic in comparison to the results of laboratory experiments [13]. Hence, more accurate research on the implementation in HAM simulations is desired. Nevertheless, this study shows the fundamental differences between urban and rural climate and the impact of a water repellent layer on the potential frost risk in these climates.

\section{Conclusions}

Urbanization has an effect on the prevailing climate in cities. In Ghent, Cfb climate, urbanization leads to an annual temperature increase of $1^{\circ} \mathrm{C}$ for July 2016 - June 2016. Consequently, the amount of freeze-thaw cycles is mitigated in the city centre by $33 \%$. Besides, the average wind speed at $2 \mathrm{~m}$ is reduced in this location. This urban climate has affects the potential frost risk of natural building stones, as seen in the HAM simulations. For this particular case there is no ice formation observed in the urban situated stone, while ice densities up to $80 \mathrm{~kg} / \mathrm{m}^{3}$ are observed in the rural situated stone. Furthermore, a water repellent layer reduces even more the frost risk as a result of the reduced amount of water present in the stone. Although these simulations show the result of a specific year on a specific stone with specific dimensions, this indicates the mitigating effect of the urban climate on deterioration of natural building stones.

\section{References}

1. C.M. Grossi, A. Bonazza, P. Brimblecombe, I. Harris, C. Sabbioni, Environ Geol. 56, 455-461 (2008)

2. P. Brimblecombe, C.M. Grossi, Sci Total Environ. 407, 1354-1361 (2009)

3. A. Bonazza, P. Messina, C. Sabbioni, C.M. Grossi, P. Brimblecombe, Sci Total Environ. 407, 2039-2050 (2009)

4. C.M. Grossi, P. Brimblecombe, B. Menéndez, D. Benavent, I. Harris, M. Déqué, Sci Total Environ. 409, 2577-2585 (2011)

5. A. Bonazz, C. Sabbioni, P. Messina, C. Guaraldi, P. De Nuntiis, Sci Total Environ. 407, 4506-4512 (2009)

6. C.M. Grossi, P. Brimblecomb, I. Harris, Sci Total Environ. 307, 273-281 (2007)

7. K.R. Lisø, T. Kvande, H.O. Hygen, J.V. Thue, K. Harstveit, Build Environ. 42, 3547-3555 (2007)

8. M. Dusar, R. Dreesen, M. De Ceukelaire, Münchner Geowissenschaftliche Abhandlungen. Reihe B, 2, 416-427 (2015)

9. S. Caluwaerts, P. Termonia, Urban Clim News. 61, 15-20 (2016)

10. F.E. Nelson, S. Outcalt, Arct Alp Res. 19, 279-288 (1987)

11. H.M. Künzel, Mater Struct Constr. 31, 99-103 (1998)

12. D. Camuffo, Sci Total Environ. 167, 1-14 (1995)

13. S. De Mol, Master Thesis UGent, (2017) 